\title{
Current concepts in the treatment of midshaft clavicle fractures in adults
}

\author{
Hyun Seok Song, Hyungsuk Kim \\ Department of Orthopedic Surgery, Eunpyeong St. Mary's Hospital, College of Medicine, The Catholic University of Korea, Seoul, Korea
}

\begin{abstract}
Midshaft clavicle fractures are the most common fracture of the clavicle accounting for $80 \%$ of all clavicle fractures. Traditionally, midshaft clavicle fractures are treated with conservative treatment even when prominent displacement is observed; however, recent studies revealed that nonunion or malunion rate may be higher with conservative treatment. Moreover, recent studies have shown better functional results and patient satisfaction with surgical treatment. This review article provides a review of clavicle anatomy, describes the current clavicle fracture classification system, and outlines various treatment options including current surgical options for clavicle fracture in adults.
\end{abstract}

Keywords: Clavicle; Shaft; Adult; Shoulder; Treatments

\section{INTRODUCTION}

Clavicle fractures are upper extremity fractures, and are one of the most common broken bones seen in the emergency room setting, accounting for 35\% to $44 \%$ of shoulder girdle fractures and $2 \%$ to $5 \%$ of all adult fractures [1-3]. Direct trauma to the clavicle, as in contact sports or motorcycle and bicycle accidents, is the most common cause of fracture. Males are more often affected than females, and clavicle fractures most commonly occur in patients younger than 30 years of age. Although $88.2 \%$ of all clavicle fractures occur in younger adults, a bimodal peak is observed in elderly patients due to simple falls from moderate height or falls from bed [4].

Most clavicle fractures occur in the midshaft accounting for about $80 \%$ of all clavicle fractures, followed by distal clavicle and medial clavicle fractures [5]. Traditionally, most clavicle fractures are treated nonoperatively; however, various strategies for the surgical treatment of displaced midshaft fractures have been reported recently, including interfragmentary screw fixation, intramedullary (IM) fixation, cerclage wiring, and plate fixation. Recently, attempts to use three-dimensional (3D) printing technology on fracture surgery have been made [6,7].

Although numerous studies have reported on the management of midshaft clavicle fractures, definitive treatment strategies have not been defined and the various surgical techniques used have not been described. In this article, we review the anatomy of the clavicle, review both surgical and nonsurgical options for midshaft clavicle fractures reported thus far, and discuss the optimal treatment options for fractured clavicles in adults.

Received: June 11, $2021 \quad$ Revised: August 24, $2021 \quad$ Accepted: August 25, 2021

Correspondence to: Hyungsuk Kim

Department of Orthopedic Surgery, Eunpyeong St. Mary's Hospital, College of Medicine, The Catholic University of Korea, 1021 Tongil-ro, Eunpyeonggu, Seoul 03312, Korea

Tel: +82-2-2030-4628, Fax: +82-2-2030-2743, E-mail: hskimosmd@daum.net, ORCID: https://orcid.org/0000-0003-3400-0263

\section{Financial support: None.}

Conflict of interest: None.

Copyright@ 2021 Korean Shoulder and Elbow Society.

This is an Open Access article distributed under the terms of the Creative Commons Attribution Non-Commercial License (http://creativecommons.org/licenses/by-nc/4.0/) which permits unrestricted non-commercial use, distribution, and reproduction in any medium, provided the original work is properly cited. 


\section{ANATOMY OF THE CLAVICLE}

The human clavicle is a unique double-curved S-shaped 3D structure with a complex morphology. It offers the only direct link between the axial and appendicular skeleton [8,9]. It is highly variable within a given population; variation exists not only in length, which is approximately 140 to $150 \mathrm{~mm}$ (range, 118-162 $\mathrm{mm}$ ) and diameter but also in its cross-section and the degree of bowing. In addition, personal deviation in human clavicle anatomy is large and variations between males and females have been reported [10-12]. Generally, the human clavicle is presumed to be anatomically symmetric; however, there are only a few studies assessing symmetricity of the human clavicle. Cunningham et al. [13] assessed side-to-side variation in clavicle length in uninjured adults with computed tomography (CT) and reported symmetry in $71.5 \%$ of all patients. A recent study by Hoogervorst et al. [14] reported that $30 \%$ of patients had side-to-side asymmetry of 5 $\mathrm{mm}$ or more, and there was a significant association between clavicle length and dominant side or sex.

The human clavicle is prone to fracture due to multiple reasons. It is one of the least-protected bones by muscle or fat, since it is located superficially just beneath the skin and platysma muscle $[1,15]$. The clavicle articulates with the sternum medially forming the sternoclavicular joint and articulates with the acromion laterally forming the acromioclavicular joint. Both joints provide stability with muscle and ligamentous support. It is a relatively thin bone with a mean cortical thickness of $2.05 \mathrm{~mm}$ at the midpoint [16]. In the middle third of the clavicle, the thin diameter, curved shape, and absence of stability provided by articulation make it prone to fracture [15]. Also, it is prone to fracture between the midshaft and distal one-third, where the midshaft tubular structure transitions to a flat shape structure distally [17].

\section{CLAVICLE FRACTURE CLASSIFICA- TION}

Several classification systems for clavicle fractures have been introduced since the 1960s. The Allman classification was first introduced in 1967 [18], which is based on anatomic location and was the first widely accepted classification system for clavicle fractures. Fractures within the middle third were referred to as type I fractures, those within the lateral third were type II fractures, and medial third were type III. Later on, Neer [19] subclassified the fractures of the lateral third, which were categorized based on the fracture location in relation to the coracoclavicular ligament that provides stability of the medial fracture segment. However, these classification systems do not consider treatment options nor prognosis of fractures [20].

Robinson [3] introduced a more detailed classification based on fracture location, adding the concept of displacement, angulation, intra-articular extension, and comminution of the fracture, where subgroups A and B include fractures displaced less than and greater than $100 \%$, respectively. The middle third fractures are also subdivided by the degree of comminution and fracture pattern, with simple or wedge-type fractures categorized as subgroup 1 and comminuted or segmental fracture patterns categorized as subgroup 2. Finally, medial and lateral fractures are subdivided based on intra-articular extensions.

For lateral clavicle fractures, Craig modified Neer type II fractures by separately classifying intra-articular and pediatric fractures by emphasizing the importance of the conoid ligament [21]. Recently, Cho et al. [22] suggested a new classification system considering fracture displacement, stability, and fracture location to help surgeons choose the most optimal treatment option for each type of fracture. This classification system defined type I fractures as stable and type II as unstable with significant displacement. Type II fractures are subcategorized into four subtypes by fracture location and whether the conoid or trapezoid ligaments are damaged.

\section{CONSERVATIVE TREATMENT}

Historically, the majority of midshaft clavicle fractures have been treated nonoperatively, famously based on two large case series by Neer [23] and Rowe [24] in the 1960s. Neer [23] reported a low nonunion rate of $0.13 \%$ within 2,234 patients and Rowe [24] reported a rate of $0.8 \%$ in 566 patients.

Immobilizing the involved shoulder with a figure-of-eight brace or bandage is the most widely used conservative treatment. The goal of applying a figure-of-eight brace is to elevate and extend the shoulder to bring the distal fragment close to the proximal fragment [24]. Recently, however, the use of sling immobilization has increased, since complaints including pain and discomfort were reported with immobilization using a figure-ofeight bandage. Moreover, there are multiple studies reporting that sling immobilization is superior to the figure-of-eight brace immobilization $[25,26]$. Although there was no difference in the rate of nonunion or union time between sling immobilization and figure-of-eight brace immobilization, lower satisfaction, lower functional scores, and higher pain scores were seen with the figure-of-eight brace immobilization. Other reported complications with the figure-of-eight brace include axillary skin irritation, temporary brachial plexus palsy, and deep venous thrombosis $[27,28]$. Immobilization is recommended for 4 to 6 weeks al- 
lowing for a passive range of motion not above $90^{\circ}$ forward flexion. In most cases, the sling or brace is removed after 6 weeks. Also, a light amount of work may be allowed but weight-bearing is allowed only at 3 months and return to sports at 4 to 6 months after injury [29,30].

The low nonunion rates reported by Neer [23] and Rowe [24] cannot avoid criticism since pediatric fractures, in which nonunion is rare, were included. Higher nonunion rates in clavicle fractures with conservative treatment were reported in many studies ranging from $7 \%$ to $15 \%$, and even with fracture union, complications such as shortening, angulation, malunion, and lower clinical outcomes were reported (Fig. 1) [29,31-33]. Recent studies excluding pediatric clavicle fractures reported a higher nonunion rate of $15 \%$ to $20 \%$ with nonoperative treatment with displaced clavicle midshaft fractures [32,34,35]. Moreover, unsatisfactory clinical outcomes and complications including cosmetic problems such as skin protrusion were reported $[32,36]$.

Shortening of the clavicle after fracture should be carefully assessed as shortening greater than $2 \mathrm{~cm}$ may be prone to nonunion [35]. Also, shortening of the clavicle can affect the biomechanical principle of the shoulder girdle by altering the moment arm of shoulder muscles. Altered biomechanics of the shoulder
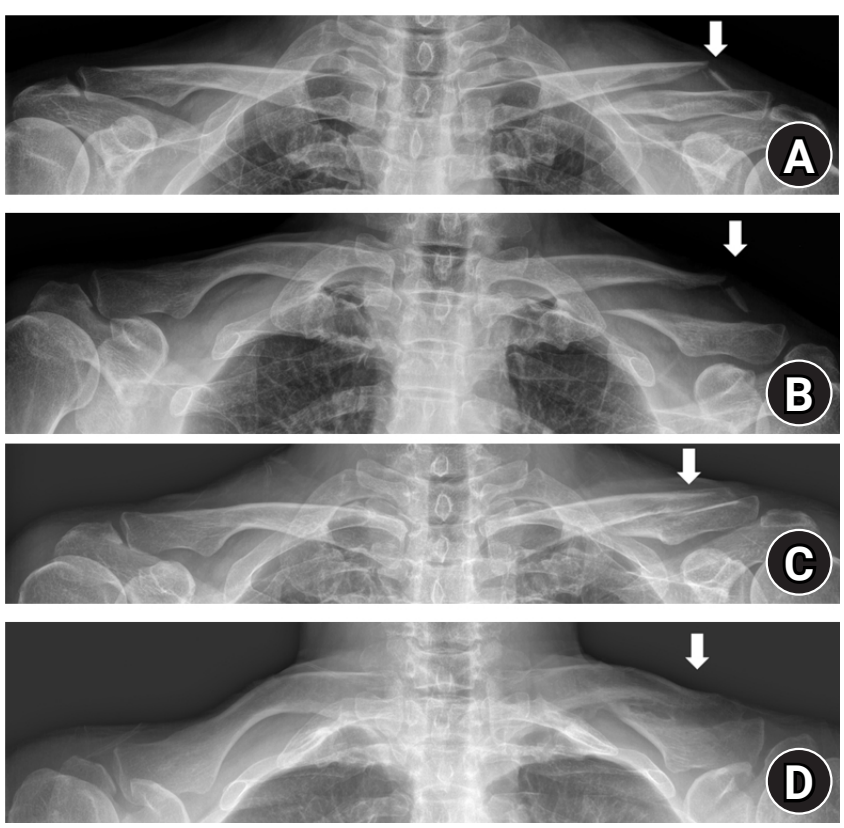

Fig. 1. Serial radiographs from a 48-year-old man with conservative treatment of a midshaft clavicle fracture with comminution and shortening. Surgical treatment was recommended initially; however, since the patient underwent multiple surgeries due to Charcot joint arthropathy in the ankle, the patient refused operative treatment. Malunion is observed 3 years post-accident on plain radiographs. (A) Initial anteroposterior (AP) view. (B) Initial caudal view. (C) AP view 3 years post-accident. (D) Caudal view on 3 years post-accident. Arrows indicate fracture site. girdle may result in muscle fatigability and impair shoulder function. Hill et al. [32] reported that initial shortening of more than $2 \mathrm{~cm}$ was highly associated with nonunion and unsatisfactory results including residual pain, evidence of brachial plexus irritation, and cosmetic problems. Wick et al. [37] recommended operative treatment for clavicle fractures with a shortening of more than $2 \mathrm{~cm}$ to avoid nonunion. In a study by Ledger et al. [38], shortening was measured by $\mathrm{CT}$ and showed that shortening greater than $1.5 \mathrm{~cm}$ was associated with weaker muscle strength compared to the contralateral side. With a self-administered shoulder questionnaire [39], the severity of symptoms was assessed and the functional status of the shoulder and poor clinical outcomes were found compared to the uninjured contralateral side. However, shortening alone as an operative indication is still in controversy. A recent systemic review conducted by Woltz et al. [40] reported that shortening alone is not an evidence-based indication for operative treatment.

\section{SURGICAL TREATMENT}

There have been many attempts to define the optimal treatment options for displaced midshaft clavicle fractures. Including the randomized controlled trial (RCT) performed by The Canadian Orthopaedic Trauma Society (COTS) [5], recent studies reported patients with open reduction and internal fixation (ORIF) showed lower rates of malunion and better clinical outcomes $[41,42]$. Although the optimal treatment for displaced midshaft clavicle fractures is not defined, it is still under investigation with multiple comparative studies comparing surgical and nonsurgical management and different methods of surgical fixation techniques.

Surgical treatment as an optimal treatment for clavicle fracture became a trend after the COTS study results were [5] released that showed the surgically treated group with superior plates showed lower rates of nonunion and faster time to union. In addition, clinical outcomes such as functional scores and satisfaction were better in the surgically treated group. The complications reported in the surgically treated group included implant irritation, wound infection, and wound dehiscence [41].

Surgical treatment, as assessed on plain radiographs when shortening is greater than $2 \mathrm{~cm}$, is considered when displacement is greater than $100 \%$ and when a Z-type fracture, which is a comminuted fracture with a displaced and rotated butterfly fragment between major fragments, is seen and notable comminution is observed [5,35]. Also, in patients with young age and high level of activity, surgical treatment may be preferred.

Plate and screw fixation is commonly accepted as a standard 
method in surgical treatment. Other surgical techniques including fixation with IM nails, cerclage wiring, interfragmentary wiring, or bioabsorbable screws have been introduced (Figs. 2 and 3). Also, based on advancements in $3 \mathrm{D}$ printing technology, surgical treatment with the aid of $3 \mathrm{D}$ printing has been introduced $[6,43,44]$.

\section{Plate and Screw Fixation}

Plate and screw ORIF is considered the gold standard surgical option. Plate and screw fixation provides rigid fixation with cortical compression and rotational control. Multiple RCTs have reported a lower nonunion rate compared with nonoperative treatment ranging from $0 \%$ to $2.8 \%$ when using plate and screw fixation $[29,40]$. However, secondary operation may be required mostly due to the prominent hardware causing cosmetic problems or implant irritation. Leroux et al. [45] reported that $25 \%$ of patients who underwent ORIF with plate and screw fixation required reoperation for removal. Other complications for plate and screw fixation include wound infection and wound dehiscence [5]. Complications around major neurovascular structures will be discussed below.

\section{Superior Plating vs. Anteroinferior Plating}

While the common plating positions are superior and anteroinferior (Fig. 4), the optimal position of the plate is still controversial. Superior plating has been traditionally used because it allows
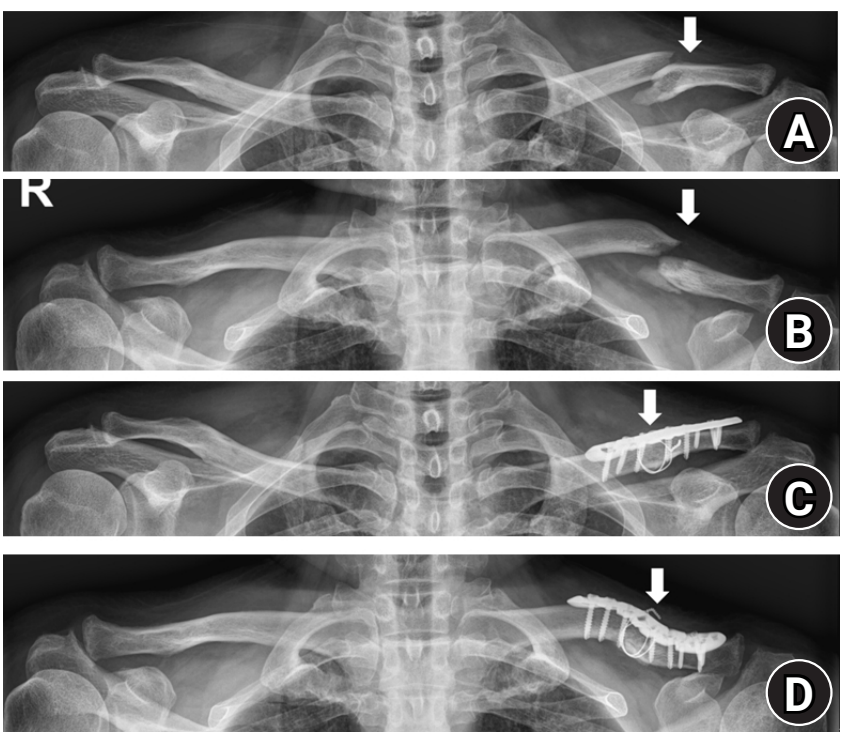

Fig. 2. Radiographs of a 63-year-old man who sustained a comminuted left midshaft clavicle fracture. (A) Anteroposterior (AP) view. (B) Caudal view. The patient underwent plate fixation with two cerclage wirings. Union was achieved in 1-year postoperative radiographs. (C) AP view. (D) Caudal view. Arrows indicate fracture site. fixation on the tension side of the fracture. However, since complications have emerged, including hardware prominence and concern on screw trajectory angle which aims toward major vas-
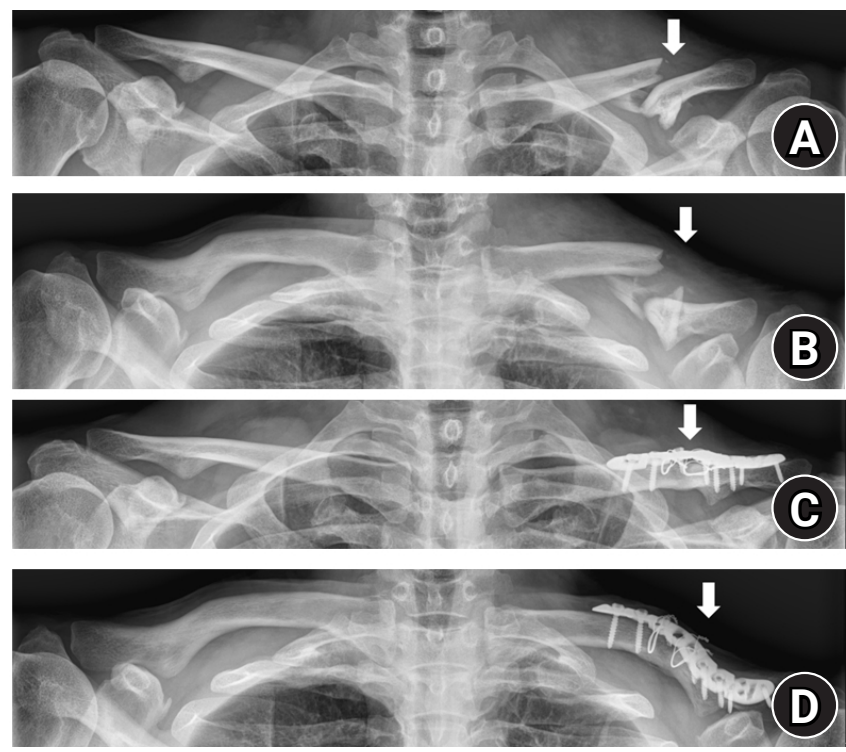

Fig. 3. Radiographs of a 60-year-old man who sustained a comminuted left midshaft clavicle fracture. (A) Anteroposterior (AP) view. (B) Caudal view. The patient underwent plate fixation with four interfragmentary wirings. Union was achieved in 1-year postoperative radiographs. (C) AP view. (D) Caudal view. Arrows indicate fracture site.
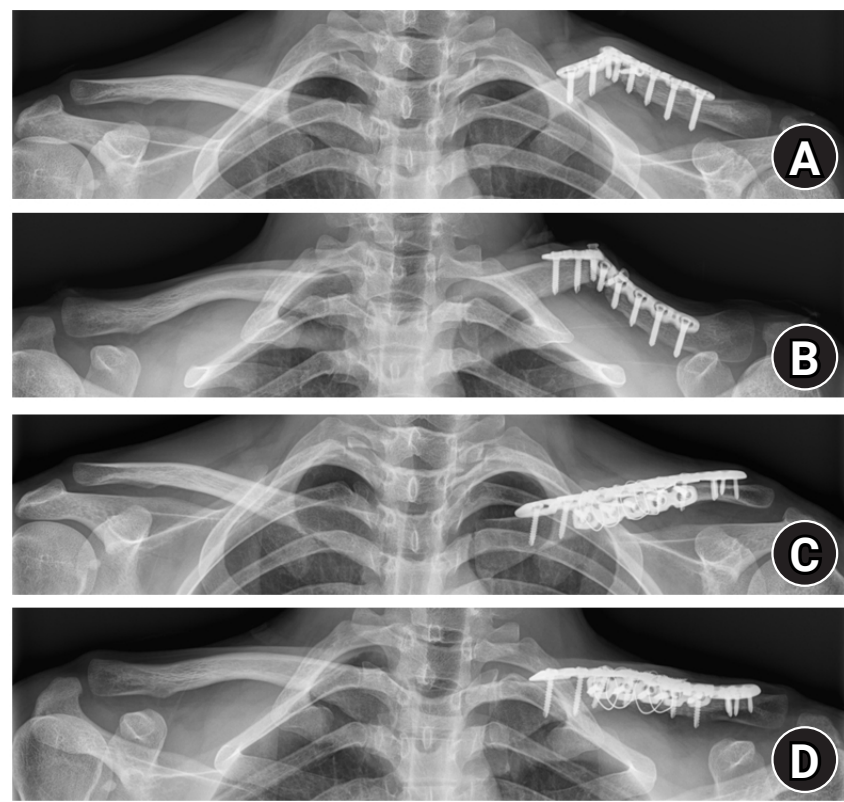

Fig. 4. Radiographs of a 23-year-old man who sustained re-fracture with metallic failure after plate fixation from another clinic. (A) Anteroposterior (AP) view. (B) Caudal view. The patient underwent double plate fixation with a superior plate and anteroinferior plate. Six-month postoperative radiographs are shown. (C) AP view. (D) Caudal view. 
cular structures, anteroinferior plating has gained attention. By placing the plate anteroinferior, screws with greater length can be used which offer more stability, especially against rotational force [46-48]. Several biomechanical studies comparing strength based on plate position have been conducted with different results. Iannotti et al. [49] reported superior plating was the strongest biomechanical construct using midshaft clavicle fracture models with a transverse osteotomy after applying axial and torsional force. On the other hand, some studies reported that anteroinferior plating led to greater resistance to cantilever bending, although there was no significant difference in resisting axial or torsional forces [46,50,51].

While the less prominent hardware in anteroinferior plating reduces the need for hardware removal later on, Hulsmans et al. [52] reported an equal rate of implant removal between the two techniques. In a study by Sohn et al. [53], no difference in implant irritation was found between the two techniques, and implant prominence problems in the study by Collinge et al. [54] were minimal. Since the location of the clavicle is superficial just beneath the skin and thin platysma muscle [15,30], surgeons must try to decrease implant irritation by meticulous dissection, which preserves the platysma fascial layer to be repaired over the plate.

\section{Precontoured Plates}

To overcome the complex 3D anatomical features of the human clavicle, anatomical precontoured plates can be used (Fig. 5). Using a precontoured plating system is expected to shorten operation time since no additional bending is needed during surgery and since the plate is precisely anatomically contoured with the bone, cosmetic problems or discomfort by skin protrusion can be

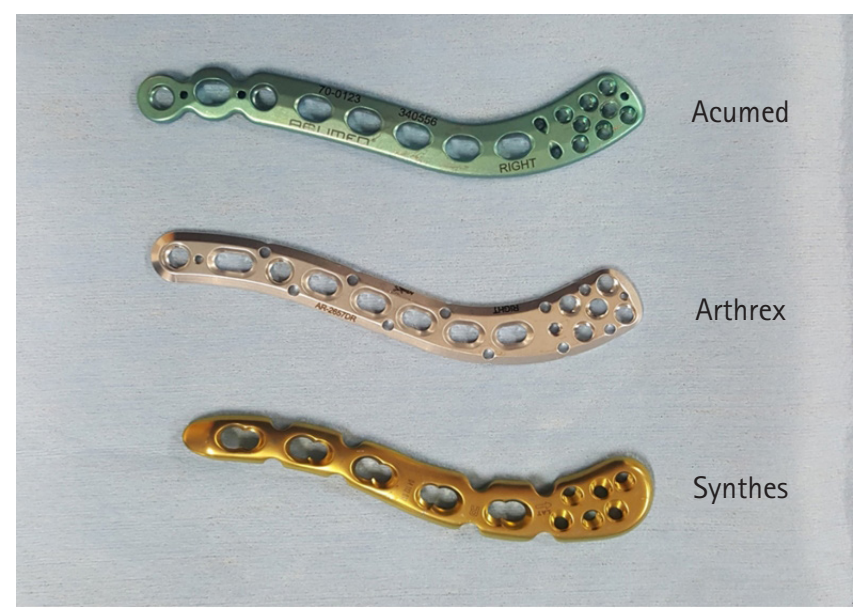

Fig. 5. Three products of anatomically precontoured clavicle plate systems. prevented. Fleming et al. [55] reported a 100\% union rating with no mandatory need for removal using precontoured plates. Chandrasenan et al. [56] revealed that pre-contoured anatomical plates that are fit to the actual clavicle shorten the operation time.

However, due to the complex anatomic features of the human clavicle and diversity among individuals, some studies reported incompatibility of precontoured plates and high rates of implant irritation leading to the need for implant removal [57,58]. Malhas et al. [57] insisted that when using a plating system, it is advantageous to have multiple plate shape variations on hand during surgery due to the anatomic diversities of the human clavicle. Huang et al. [59] revealed that the apex of the superior bow was located on the lateral aspect of the clavicle, making the pre-contoured plate difficult to fit laterally.

\section{Locking vs. Non-locking Plates}

After their introduction, locking plates have been very popular for use with clavicle fractures. Locking plates have advantages for use with osteoporotic bone in that they lead to stronger fixation providing minimal contact between the bone and plate, preserving bone blood supply. Locking plates are also used in minimally invasive percutaneous plate osteosynthesis (MIPO). By avoiding periosteal stripping with soft tissue preservation, locking plates with the MIPO technique in clavicle fractures have reported rapid union [10]. On the other hand, concerns with the MIPO technique include the possibility of relatively large fracture gaps, which may result in poor secondary bone healing and shortened or lengthened clavicular malunion leading to functional deficits [60]. Also, strong soft tissue dissection is seldom required to advance the plate and rare complications such as pneumothorax have been reported after MIPO for midshaft clavicle fractures [61]. However, there are multiple studies supporting good clinical and radiologic outcomes using the MIPO technique for clavicle shaft fractures [62-64].

A prospective randomized trial comparing locking superior plate fixation and non-locking superior plate fixation for displaced midshaft fractures was reported. Complication rates and clinical results were similar; however, time to union was shorter with the locking plate group [65].

\section{Complications (Neurovascular Risks) of Plate Fixation}

Longitudinal incisions over the clavicle are generally used since vertical incisions have limitations in surgical exposure making it difficult to use longer plates. With longitudinal incisions, it is easy to extend the incision intraoperatively when necessary. During surgical approaches with longitudinal incision, branches of the supraclavicular nerves are at risk. When damaged on the 
way of approach to the fracture, sensory disorders such as desensitization may occur in the supraclavicular and infraclavicular region, anteromedial aspect of the shoulder, and/or anterosuperior region of chest wall. Wang et al. [66] reported $83 \%$ of sensory disorders after plate fixation in clavicle fractures and recommended using the vertical incision.

In addition to superficial sensory disorders, major neurovascular structures located beneath and posterior to the clavicle are a main concern in plate fixation. Damage to the major neurovascular structure during plate fixation is uncommon. Leroux et al. [45] reported only five neurologic complications and five vascular complications out of 1,350 clavicle fractures treated with plate fixation. Caution should be taken when fixation is performed on the medial half. In a cadaveric study by Galley et al. [67], the vascular risk was high in the most medial quarter. On the posterior side of the most medial quarter of the clavicle, the common carotid artery and in particular the internal jugular vein axis is at risk when drilling anterior to posterior. This was later supported by an image study performed by Sinha et al. [68] that showed in their contrast-enhanced CT assessment that drilling should be directed superiorly in the most medial quarter and posteriorly in the second medial quarter. They also suggested superior plating in two medial segments, when divided into three zones, rather than placing the plate on the anterior edge.

\section{Intramedullary Nailing}

IM nailing is another good option for surgically treating displaced midshaft clavicle fractures, with comparable results to plate fixation reported in some studies [69-71]. Its advantages include small incisions with less soft tissue dissection, which prevents supraclavicular nerve injury and promotes fracture healing. Also, IM nailing avoids the possibility of damaging major neurovascular structures located beneath the clavicle by drilling or protruded screws when performing plate fixation.

Indications for IM fixation are not different from those for plate fixation. However, severely comminuted fractures or segmental fractures may be contraindications for IM nailing [72]. Implants used in IM nailing include Kirschner wires (K-wires), titanium elastic nails (TENs; Synthes, West Chester, PA, USA), IM screws, and Hagie pins (Smith \& Nephew, Andover, MA, USA). There are a number of studies reporting a $100 \%$ healing rate using IM nailing whether with Hagie pins or TENs [72]. A meta-analysis by Duan et al. [73] reported a higher rate of union and better functional outcomes with IM nails compared to conservative treatment.

Complication rates are relatively high in IM nailing, as Strauss et al. [74] reported a complication rate of $50 \%$ and van der Meij- den et al.[70] reported an 85\% complication rate. The most common complication using IM nailing is superficial infection around the exposed implant, which includes pin extrusion, skin irritation, or erosion. Other reported complications are implant failure including breakage or bending of the implant.

The better surgical treatment option between plate fixation and IM nailing is unclear as incompatible results have been shown in biomechanical studies. Zeng et al. [69] reported that IM nailing showed more physiologic stress distribution but with greater displacement and implant stresses under axial loads and cantilever bending force compared to plate fixation. However, $\mathrm{Ni}$ et al. [75] reported that plate fixation showed an even stress distribution and recommended plate fixation over IM nailing. Another biomechanical analysis using sawbones by Wilson at al. [76] showed that rotational stability was superior with plate fixation compared to IM nailing. In a systemic review by Hulsmans et al. [77], rotational stiffness did not differ significantly; however, plate fixation was superior in torque stiffness. Moreover, plate fixation showed more construct stiffness in a three-point bending test, where both ends of the clavicle were embedded and the load was applied superior to the inferior direction, and cantilever bending test compared to IM nailing.

In clinical studies, a systemic review by Houwert et al. [78] concluded no differences in functional outcomes or complications after plate fixation or IM nailing; however, the results of RCTs performed later showed evidence to the contrary. van der Meijden et al. [70] found that patients with plate fixation had less disability six months from surgery and more patients needed implant removal due to implant irritation in patients treated with IM nailing. Andrade-Silva et al. [71] reported that although no difference was found in time to union or complications, implant irritation rate was higher at $40 \%$ in the IM nailing group and at $14 \%$ in the plate fixation group. Park et al. [79] reported higher satisfaction with IM nailing, but early postoperative pain and fracture migration were higher with IM nailing, especially in the multi-fragmentary fracture type, suggesting plate fixation in this particular fracture type. A systemic review showed no differences in function or nonunion rate between the two methods, but after implant removal, patients with plate fixation were prone to re-intervention and refracture [80].

\section{Three-Dimensional Printing-Assisted Surgery}

3D printing technology has been widely used in orthopedics over the last decade. It has been actively applied in implant design and surgical guides in orthopedics $[81,82]$. Due to the complex anatomy and diversity between individuals, 3D printing technology aids surgeons to treat clavicle fractures by helping to choose the 

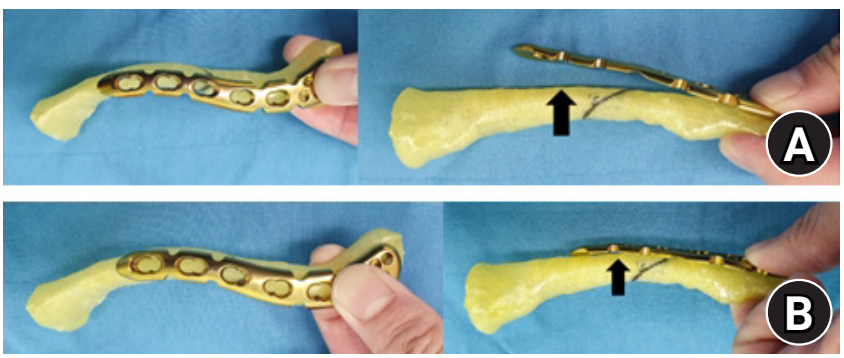

Fig. 6. Bending the plate preoperatively using a three-dimensional (3D) printed model. The plate was bent using benders to match the contour between the $3 \mathrm{D}$ printed model and the plate on the best fit location. (A) Arrow indicates a gap between plate and 3D printed model before bending. (B) Arrow indicates resolution of a gap after bending.

optimal implant and precontouring the implant preoperatively (Fig. 6).

Kim et al. [6] described a technique using a 3D printed clavicle model to choose the most suitable plate preoperatively. By choosing the best fit plate, displaced comminuted midshaft clavicle fractures were treated with the MIPO technique. van Doremalen et al. [43] adjusted the plate preoperatively with $3 \mathrm{D}$ printed models and suggested preoperative preparation with $3 \mathrm{D}$ printed models may reduce implant removal caused by plate-related discomfort. Fillat-Gomà et al. [44] showed improvement and enhanced surgical planning not only in clavicle fractures but also in other upper extremity fractures by $3 \mathrm{D}$ printing technology. They also applied the plate on a 3D-printed clavicle model and choose the best fitting plate with optimal stability.

There are some obstacles to overcome when using 3D printing technology. First, considerable time and cost is required. Particular CT data using a thin-slice CT protocol is required for reconstruction. Moreover to manufacture a $3 \mathrm{D}$-printed model, a $3 \mathrm{D}$ printing system with adequate space is essential. Further studies are needed to prove the benefit of $3 \mathrm{D}$ printing technology, including cost-effectiveness. Second, further studies are needed to assess the symmetricity of the clavicle since the contralateral intact clavicle is used as a reference.

\section{CONCLUSION}

Midshaft clavicle fractures are common upper extremity injuries in adults. Although conservative treatment is the optimal treatment for nondisplaced clavicle fractures, it is still hard to say whether surgical or nonsurgical treatment is the optimal treatment option for displaced midshaft clavicle fractures. However, a consensus has been reached on high nonunion rates for displaced midshaft fractures in adults. Surgical treatment is recommended when shortening is greater than $2 \mathrm{~cm}$, displacement is greater than $100 \%$, Z-type fractures are present, and notable comminution is observed.

\section{ORCID}

Hyun Seok Song https://orcid.org/0000-0002-7844-2293

Hyungsuk Kim

https://orcid.org/0000-0003-3400-0263

\section{REFERENCES}

1. Khan LA, Bradnock TJ, Scott C, Robinson CM. Fractures of the clavicle. J Bone Joint Surg Am 2009;91:447-60.

2. Nordqvist A, Petersson C, Redlund-Johnell I. The natural course of lateral clavicle fracture: 15 (11-21) year follow-up of 110 cases. Acta Orthop Scand 1993;64:87-91.

3. Robinson CM. Fractures of the clavicle in the adult: epidemiology and classification. J Bone Joint Surg Br 1998;80:476-84.

4. Postacchini F, Gumina S, De Santis P, Albo F. Epidemiology of clavicle fractures. J Shoulder Elbow Surg 2002;11:452-6.

5. Canadian Orthopaedic Trauma Society. Nonoperative treatment compared with plate fixation of displaced midshaft clavicular fractures: a multicenter, randomized clinical trial. J Bone Joint Surg Am 2007;89:1-10.

6. Kim HN, Liu XN, Noh KC. Use of a real-size 3D-printed model as a preoperative and intraoperative tool for minimally invasive plating of comminuted midshaft clavicle fractures. J Orthop Surg Res 2015;10:91.

7. Kim JW, Lee Y, Seo J, et al. Clinical experience with three-dimensional printing techniques in orthopedic trauma. J Orthop Sci 2018;23:383-8

8. Balcik BJ, Monseau AJ, Krantz W. Evaluation and treatment of sternoclavicular, clavicular, and acromioclavicular injuries. Prim Care 2013;40:911-23.

9. Van Tassel D, Owens BD, Pointer L, Moriatis Wolf J. Incidence of clavicle fractures in sports: analysis of the NEISS Database. Int J Sports Med 2014;35:83-6.

10. Abdel Fatah EE, Shirley NR, Mahfouz MR, Auerbach BM. A three-dimensional analysis of bilateral directional asymmetry in the human clavicle. Am J Phys Anthropol 2012;149:547-59.

11. Auerbach BM, Raxter MH. Patterns of clavicular bilateral asymmetry in relation to the humerus: variation among humans. J Hum Evol 2008;54:663-74.

12. Daruwalla ZJ, Courtis P, Fitzpatrick C, Fitzpatrick D, Mullett H. Anatomic variation of the clavicle: a novel three-dimensional study. Clin Anat 2010;23:199-209.

13. Cunningham BP, McLaren A, Richardson M, McLemore R. 
Clavicular length: the assumption of symmetry. Orthopedics 2013;36:e343-7.

14. Hoogervorst P, Appalsamy A, Franken S, van Kampen A, Hannink G. Quantifying shortening of the fractured clavicle assuming clavicular symmetry is unreliable. Arch Orthop Trauma Surg 2018;138:803-7.

15. Jeray KJ. Acute midshaft clavicular fracture. J Am Acad Orthop Surg 2007;15:239-48.

16. Andermahr J, Jubel A, Elsner A, et al. Anatomy of the clavicle and the intramedullary nailing of midclavicular fractures. Clin Anat 2007;20:48-56.

17. Bachoura A, Deane AS, Wise JN, Kamineni S. Clavicle morphometry revisited: a 3-dimensional study with relevance to operative fixation. J Shoulder Elbow Surg 2013;22:e15-21.

18. Allman FL Jr. Fractures and ligamentous injuries of the clavicle and its articulation. J Bone Joint Surg Am 1967;49:774-84.

19. Neer CS 2nd. Fracture of the distal clavicle with detachment of the coracoclavicular ligaments in adults. J Trauma 1963;3:99110.

20. O'Neill BJ, Hirpara KM, O'Briain D, McGarr C, Kaar TK. Clavicle fractures: a comparison of five classification systems and their relationship to treatment outcomes. Int Orthop 2011;35: 909-14.

21. Rockwood CA, Bucholz RW, Green DP. Rockwood and Green's fractures in adults. 6th ed. Philadelphia, PA: Lippincott Williams \& Wilkins; 2006.

22. Cho CH, Kim BS, Kim DH, Choi CH, Dan J, Lee H. Distal clavicle fractures: a new classification system. Orthop Traumatol Surg Res 2018;104:1231-5.

23. Neer CS 2nd. Nonunion of the clavicle. J Am Med Assoc 1960; 172:1006-11.

24. Rowe CR. An atlas of anatomy and treatment of midclavicular fractures. Clin Orthop Relat Res 1968;58:29-42.

25. Ersen A, Atalar AC, Birisik F, Saglam Y, Demirhan M. Comparison of simple arm sling and figure of eight clavicular bandage for midshaft clavicular fractures: a randomised controlled study. Bone Joint J 2015;97:1562-5.

26. Andersen K, Jensen PO, Lauritzen J. Treatment of clavicular fractures: figure-of-eight bandage versus a simple sling. Acta Orthop Scand 1987;58:71-4.

27. Stanley D, Norris SH. Recovery following fractures of the clavicle treated conservatively. Injury 1988;19:162-4.

28. Lenza M, Belloti JC, Andriolo RB, Faloppa F. Conservative interventions for treating middle third clavicle fractures in adolescents and adults. Cochrane Database Syst Rev 2014;(5): CD007121.

29. Robinson CM, Goudie EB, Murray IR, et al. Open reduction and plate fixation versus nonoperative treatment for displaced midshaft clavicular fractures: a multicenter, randomized, controlled trial. J Bone Joint Surg Am 2013;95:1576-84.

30. Preston CF, Egol KA. Midshaft clavicle fractures in adults. Bull NYU Hosp Jt Dis 2009;67:52-7.

31. Nowak J, Holgersson M, Larsson S. Can we predict long-term sequelae after fractures of the clavicle based on initial findings? A prospective study with nine to ten years of follow-up. J Shoulder Elbow Surg 2004;13:479-86.

32. Hill JM, McGuire MH, Crosby LA. Closed treatment of displaced middle-third fractures of the clavicle gives poor results. J Bone Joint Surg Br 1997;79:537-9.

33. Gossard JM. Closed treatment of displaced middle-third fractures of the clavicle gives poor results. J Bone Joint Surg Br 1998; 80:558.

34. McKee MD. Displaced fractures of the clavicle: who should be fixed?: commentary on an article by C.M. Robinson, FRCSEd (Tr\&Orth) et al.: "Open eduction and plate fixation versus nonoperative treatment for displaced midshaft clavicular fractures. a multicenter, randomized, controlled trial". J Bone Joint Surg Am 2013;95:e1291-2.

35. McKee MD, Pedersen EM, Jones C, et al. Deficits following nonoperative treatment of displaced midshaft clavicular fractures. J Bone Joint Surg Am 2006;88:35-40.

36. Lazarides S, Zafiropoulos G. Conservative treatment of fractures at the middle third of the clavicle: the relevance of shortening and clinical outcome. J Shoulder Elbow Surg 2006;15:191-4.

37. Wick M, Müller EJ, Kollig E, Muhr G. Midshaft fractures of the clavicle with a shortening of more than $2 \mathrm{~cm}$ predispose to nonunion. Arch Orthop Trauma Surg 2001;121:207-11.

38. Ledger M, Leeks N, Ackland T, Wang A. Short malunions of the clavicle: an anatomic and functional study. J Shoulder Elbow Surg 2005;14:349-54.

39. L'Insalata JC, Warren RF, Cohen SB, Altchek DW, Peterson MG. A self-administered questionnaire for assessment of symptoms and function of the shoulder. J Bone Joint Surg Am 1997;79: 738-48.

40. Woltz S, Sengab A, Krijnen P, Schipper IB. Does clavicular shortening after nonoperative treatment of midshaft fractures affect shoulder function? A systematic review. Arch Orthop Trauma Surg 2017;137:1047-53.

41. McKee RC, Whelan DB, Schemitsch EH, McKee MD. Operative versus nonoperative care of displaced midshaft clavicular fractures: a meta-analysis of randomized clinical trials. J Bone Joint Surg Am 2012;94:675-84.

42. Zlowodzki M, Zelle BA, Cole PA, Jeray K, McKee MD; Evidence-Based Orthopaedic Trauma Working Group. Treatment 
of acute midshaft clavicle fractures: systematic review of 2144 fractures: on behalf of the Evidence-Based Orthopaedic Trauma Working Group. J Orthop Trauma 2005;19:504-7.

43. van Doremalen RF, van der Linde RA, Kootstra JJ, van Helden SH, Hekman EE. Can 3D-printing avoid discomfort-related implant removal in midshaft clavicle fractures? A four-year follow-up. Arch Orthop Trauma Surg 2020 Oct 31 [Epub]. https:// doi.org/10.1007/s00402-020-03654-6.

44. Fillat-Gomà F, Marcano-Fernández FA, Coderch-Navarro S, Martínez-Carreres L, Berenguer A. 3D printing innovation: new insights into upper extremity surgery planning. Injury 2021 Feb 13 [Epub]. https://doi.org/10.1016/j.injury. 2021.01. 048.

45. Leroux T, Wasserstein D, Henry P, et al. Rate of and risk factors for reoperations after open reduction and internal fixation of midshaft clavicle fractures: a population-based study in Ontario, Canada. J Bone Joint Surg Am 2014;96:1119-25.

46. Partal G, Meyers KN, Sama N, et al. Superior versus anteroinferior plating of the clavicle revisited: a mechanical study. J Orthop Trauma 2010;24:420-5.

47. Lo EY, Eastman J, Tseng S, Lee MA, Yoo BJ. Neurovascular risks of anteroinferior clavicular plating. Orthopedics 2010;33:21.

48. Formaini N, Taylor BC, Backes J, Bramwell TJ. Superior versus anteroinferior plating of clavicle fractures. Orthopedics 2013; 36:e898-904.

49. Iannotti MR, Crosby LA, Stafford P, Grayson G, Goulet R. Effects of plate location and selection on the stability of midshaft clavicle osteotomies: a biomechanical study. J Shoulder Elbow Surg 2002;11:457-62.

50. Toogood P, Coughlin D, Rodriguez D, Lotz J, Feeley B. A biomechanical comparison of superior and anterior positioning of precontoured plates for midshaft clavicle fractures. Am J Orthop (Belle Mead NJ) 2014;43:E226-31.

51. Favre P, Kloen P, Helfet DL, Werner CM. Superior versus anteroinferior plating of the clavicle: a finite element study. J Orthop Trauma 2011;25:661-5.

52. Hulsmans MH, van Heijl M, Houwert RM, et al. High irritation and removal rates after plate or nail fixation in patients with displaced midshaft clavicle fractures. Clin Orthop Relat Res 2017;475:532-9.

53. Sohn HS, Shon MS, Lee KH, Song SJ. Clinical comparison of two different plating methods in minimally invasive plate osteosynthesis for clavicular midshaft fractures: a randomized controlled trial. Injury 2015;46:2230-8.

54. Collinge C, Devinney S, Herscovici D, DiPasquale T, Sanders R. Anterior-inferior plate fixation of middle-third fractures and nonunions of the clavicle. J Orthop Trauma 2006;20:680-6.
55. Fleming MA, Dachs R, Maqungo S, du Plessis JP, Vrettos BC, Roche SJ. Angular stable fixation of displaced distal-third clavicle fractures with superior precontoured locking plates. J Shoulder Elbow Surg 2015;24:700-4.

56. Chandrasenan J, Espag M, Dias R, Clark DI. The use of anatomic precontoured plates in the treatment of midshaft clavicle fractures. Orthopaedic Proceedings 2009;91:179-80.

57. Malhas AM, Skarparis YG, Sripada S, Soames RW, Jariwala AC. How well do contoured superior midshaft clavicle plates fit the clavicle? A cadaveric study. J Shoulder Elbow Surg 2016;25:9549.

58. Rongguang A, Zhen J, Jianhua Z, Jifei S, Xinhua J, Baoqing Y. Surgical treatment of displaced midshaft clavicle fractures: precontoured plates versus noncontoured plates. J Hand Surg Am 2016;41:e263-6.

59. Huang JI, Toogood P, Chen MR, Wilber JH, Cooperman DR. Clavicular anatomy and the applicability of precontoured plates. J Bone Joint Surg Am 2007;89:2260-5.

60. Smekal V, Deml C, Irenberger A, et al. Length determination in midshaft clavicle fractures: validation of measurement. J Orthop Trauma 2008;22:458-62.

61. Kim MK, Lee HJ, You AH, Kang HY. Pneumothorax after minimally invasive plate osteosynthesis for midshaft clavicle fracture: a case report. Medicine (Baltimore) 2019;98:e16836.

62. Sohn HS, Shin SJ, Kim BY. Minimally invasive plate osteosynthesis using anterior-inferior plating of clavicular midshaft fractures. Arch Orthop Trauma Surg 2012;132:239-44.

63. Sohn HS, Kim WJ, Shon MS. Comparison between open plating versus minimally invasive plate osteosynthesis for acute displaced clavicular shaft fractures. Injury 2015;46:1577-84.

64. Sohn HS, Kim BY, Shin SJ. A surgical technique for minimally invasive plate osteosynthesis of clavicular midshaft fractures. J Orthop Trauma 2013;27:e92-6.

65. Uchiyama Y, Handa A, Omi H, et al. Locking versus nonlocking superior plate fixations for displaced midshaft clavicle fractures: a prospective randomized trial comparing clinical and radiografic results. J Orthop Sci 2020 Nov 8 [Epub]. https://doi. org/10.1016/j.jos.2020.09.017.

66. Wang K, Dowrick A, Choi J, Rahim R, Edwards E. Post-operative numbness and patient satisfaction following plate fixation of clavicular fractures. Injury 2010;41:1002-5.

67. Galley IJ, Watts AC, Bain GI. The anatomic relationship of the axillary artery and vein to the clavicle: a cadaveric study. J Shoulder Elbow Surg 2009;18:e21-5.

68. Sinha A, Edwin J, Sreeharsha B, Bhalaik V, Brownson P. A radiological study to define safe zones for drilling during plating of clavicle fractures. J Bone Joint Surg Br 2011;93:1247-52. 
69. Zeng L, Wei H, Liu Y, et al. Titanium elastic nail (TEN) versus reconstruction plate repair of midshaft clavicular fractures: a finite element study. PLoS One 2015;10:e0126131.

70. van der Meijden OA, Houwert RM, Hulsmans M, et al. Operative treatment of dislocated midshaft clavicular fractures: plate or intramedullary nail fixation? A randomized controlled trial. J Bone Joint Surg Am 2015;97:613-9.

71. Andrade-Silva FB, Kojima KE, Joeris A, Santos Silva J, Mattar R Jr. Single, superiorly placed reconstruction plate compared with flexible intramedullary nailing for midshaft clavicular fractures: a prospective, randomized controlled trial. J Bone Joint Surg Am 2015;97:620-6.

72. Eichinger JK, Balog TP, Grassbaugh JA. Intramedullary fixation of clavicle fractures: anatomy, indications, advantages, and disadvantages. J Am Acad Orthop Surg 2016;24:455-64.

73. Duan X, Zhong G, Cen S, Huang F, Xiang Z. Plating versus intramedullary pin or conservative treatment for midshaft fracture of clavicle: a meta-analysis of randomized controlled trials. J Shoulder Elbow Surg 2011;20:1008-15.

74. Strauss EJ, Egol KA, France MA, Koval KJ, Zuckerman JD. Complications of intramedullary Hagie pin fixation for acute midshaft clavicle fractures. J Shoulder Elbow Surg 2007;16:2804.

75. Ni M, Niu W, Wong DW, Zeng W, Mei J, Zhang M. Finite element analysis of locking plate and two types of intramedullary nails for treating mid-shaft clavicle fractures. Injury 2016;47:
1618-23.

76. Wilson DJ, Scully WF, Min KS, Harmon TA, Eichinger JK, Arrington ED. Biomechanical analysis of intramedullary vs. superior plate fixation of transverse midshaft clavicle fractures. J Shoulder Elbow Surg 2016;25:949-53.

77. Hulsmans MH, van Heijl M, Houwert RM, et al. Surgical fixation of midshaft clavicle fractures: a systematic review of biomechanical studies. Injury 2018;49:753-65.

78. Houwert RM, Wijdicks FJ, Steins Bisschop C, Verleisdonk EJ, Kruyt M. Plate fixation versus intramedullary fixation for displaced mid-shaft clavicle fractures: a systematic review. Int Orthop 2012;36:579-85.

79. Park JS, Ko SH, Hong TH, et al. Plate fixation versus titanium elastic nailing in midshaft clavicle fractures based on fracture classifications. J Orthop Surg (Hong Kong) 2020;28:23094990 20972204.

80. Xie L, Zhao Z, Zhang S, Hu Y. Intramedullary fixation versus plate fixation for displaced mid-shaft clavicle fractures: a systematic review of overlapping meta-analyses. Medicine (Baltimore) 2018;97:e9752.

81. Chuang TY, Adams CR, Burkhart SS. Use of preoperative three-dimensional computed tomography to quantify glenoid bone loss in shoulder instability. Arthroscopy 2008;24:376-82.

82. Galvez M, Asahi T, Baar A, et al. Use of three-dimensional printing in orthopaedic surgical planning. J Am Acad Orthop Surg Glob Res Rev 2018;2:e071. 